\title{
Prevalence of Klebsiella pneumoniae Encoding Genes for Ctx-M-1, Tem-1 and Shv-1 Extended-Spectrum Beta Lactamases (ESBL) Enzymes in Clinical Specimens
}

\author{
Azar Dokht Khosravi ${ }^{1,2}$, Hajar Hoveizavi ${ }^{1, *}$, Manijeh Mehdinejad ${ }^{2}$ \\ ${ }^{1}$ Health Research Institute, Infectious and Tropical Diseases Research Center, Jundishapur University of Medical Sciences, Ahvaz, IR Iran \\ ${ }^{2}$ Department of Microbiology, School of Medicine, Jundishapur University of Medical Sciences, Ahvaz, IR Iran \\ ${ }^{*}$ Corresponding author: Hajar Hoveizavi, Health Research Institute, Infectious and Tropical Diseases Research Center, Jundishapur University of Medical Sciences, Ahvaz, IR Iran. Tel/ \\ fax:+98-6113738392, E-mail: h.hoveizavi55@gmail.com.
}

Received: September 20, 2012; Revised: December 26, 2012; Accepted: January 27, 2013

\begin{abstract}
Background: Infections caused by Gram negative bacteria, producing extended-spectrum $\beta$-lactamase (ESBL), including Klebsiella pneumoniae are increasing all over the world with high morbidity and mortality.

Objectives: The aim of this study was to determine the prevalence of $K$. pneumoniae encoding the CTX-M, TEM-1 and SHV-1 ESBL enzymes genes, isolated from clinical specimens.

Materials and Methods: A total of 500 Entrobacteriaceae isolates were collected and identified using traditional culturing and biochemical tests. Antibiotic susceptibility testing was performed by disc-diffusion method according to the CLSI guideline. Screening of ESBLs was undertaken using Combination Disc Method. PCR technique was used to detect SHV-1, TEM-1 and CTX-M-1 genes according to the standard protocol.

Results: Fifty five (11\%) out of 500 tested Entrobacteriaceae isolates were identified as K. pneumoniae possessing 26 (47.27\%) ESBL positives amongst them. ESBLs positives showed the highest resistance to amoxicillin-clavulanic acid (100\%), followed by amoxicillin (97.89\%) and ampicillin (96.36\%). Imipenem and meropenem showed the highest antibacterial activity against ESBL producing K.pneumoniae. Based on the results of PCR, the prevalence of SHV-1, TEM-1 and CTX-M-1 genes among ESBLs-positive isolates was 12 (46.15\%), 9 (34.61\%), and 7 (26.92\%) respectively. TEM-1 and SHV-1 were seen in four isolates (15.38\%) simultaneously.

Conclusions: In conclusion, the rate of ESBL-producing K. pneumoniae was $47.27 \%$ in the present study, representing their commonness in our institute resistance to many classes of antibiotic, resulting in limited treatment options. Since the management of infections caused by these organisms is difficult, it is important to control such strains closely in order to prevent and reduce their spread.
\end{abstract}

Keywords: Beta-Lactamases; K. penumoniae; Polymerase Chain Reaction; Antibiotic

\section{Background}

Klebsiella pneumoniae (K. pneumoniae) is one of the most common Gram-negative bacteria showing resistance to multiple antibiotics Worldwide (1). Since the 1980s, extended-spectrum $\beta$-lactamase (ESBL)-producing Gramnegative bacteria have been isolated in many countries (2), and infections by ESBL-strains cause increased morbidity and mortality (3). These are a group of enzymes that are capable of hydrolyzing the third-generation cephalosporins, such as cefotaxime, ceftazidime, ceftriaxone, and the monobactam group of antibiotics, such as aztreonam, thus causing resistance to these antibiotics in ESBL-producing bacteria. ESBL is predominantly found in Klebsiellae spp. and Escherichia coli, and other members of the Enterobacteriaceae (4). The most prevalent ESBLs are included in three groups: TEM, SHV and CTX-M (5).
The majority of ESBLs identified in clinical isolates to date, have been SHV or TEM types, which have evolved from narrow spectrum $\beta$-lactamase such as TEM-1, TEM2 , and SHV-1 (6). Genes encoding these enzymes are located on transferable plasmids that often carry other resistance factors, including resistance to aminoglycosides (7). The first plasmid-mediated $\beta$-lactamase in Gram-negative bacteria, TEM-1, was described in the early 1960s. TEM-1 is able to hydrolyze penicillins and early cephalosporins (8). Another common plasmid-mediated $\beta$-lactamase that is found in K. pneumoniae and E. coli is SHV-1 (for sulphydryl variable) (9). Members of the SHV family of $\beta$-lactamases trace their descent to SHV-1, a plasmid-encoded $\beta$-lactamase that confers to K. pneumoniae high levels of resistance against ampicillin (10).

Additionally, a new series of ESBL enzymes, cefotaximases (CTX-M), resulting in higher MICs of cefotaxime

Implication for health policy/practice/research/medical education:

The findings of this study reflect the increasing emergence of antibiotic-resistant infections caused by enteric Gram negative bacteria in the region of study, providing useful information for HAI surveillance in teaching hospitals for a better management of infections caused by highly resistant organisms belonged to Enterobacteriaceae family.

Copyright (C) 2013, Ahvaz JundishapurUniversity of Medical Sciences; Published by Kowsar Corp. This is an open-access article distributed under the terms of the Creative Commons Attribution License, which permits unrestricted use, distribution, and reproduction in any medium, provided the original work is properly cited. 
and ceftriaxone than of ceftazidime, has been discovered in several members of the Enterobacteriaceae family and in various countries (11). The first CTX-M-type $\beta$-lactamases were identified as plasmid-encoded enzymes in clinical isolates of Entrobacteriaceae (12). CTXM-type $\beta$-lactamases are increasingly becoming the predominant ESBLs globally in the recent years, as opposed to the conventional TEM and SHV-Type ESBLs (13). In contrast with TEM and SHV ESBLs, most of the CTX-M enzymes preferentially hydrolyze and confer resistance to cefotaxime and ceftriaxone rather than ceftazidime (14). CTX-M type ESBLs show only $40 \%$ identity to TEM or SHV ESBLs, but they are closely related to $\beta$-lactamases of the Kluyvera spp. (15).

\section{Objectives}

The aim of this study was to determine the prevalence of $K$. pneumoniae encoding genes for CTX-M, TEM- 1 and SHV-1 ESBL enzymes isolated from clinical specimens in the University teaching hospitals, Ahvaz, Iran.

\section{Material and Methods}

\subsection{Bacterial Isolates}

In an 11-month study from August 2011 to July 2012, 500 Entrobacteriaceae isolates were collected from patients in Golestan and Razi teaching hospitals, Ahvaz, Iran. After immediate transferring of isolates to the laboratory of Infectious and Tropical Diseases Research center of the university, they were examined by traditional culture and biochemical identification tests (16). The confirmed clinical isolates of K. pneumoniae were stored in Tryptic soy broth (HiMedia, India) $+15 \%$ glycerol at the temperature of $-70^{\circ} \mathrm{C}$.

\subsection{Antimicrobial Susceptibility Testing}

Antibiotic susceptibility testing was performed by discdiffusion method on Mueller Hinton agar medium (Hi Media, India) and the results were interpreted according to the current guidelines of Clinical Laboratory Standards Institute [CLSI] (17). The tested antibiotic discs were: Ampicillin $(10 \mu \mathrm{g})$, Amikacin $(30 \mu \mathrm{g})$, Amoxicillin $(25 \mu \mathrm{g})$, Amoxicillin/clavulanic acid $(20 / 10 \mu \mathrm{g})$, Piperacillin (100 $\mu \mathrm{g})$, Cefuroxime (30 $\mu \mathrm{g})$, Piperacillin/tazobactame (100/10 $\mu \mathrm{g})$, Cefotaxime $(30 \mu \mathrm{g})$, Ceftazidime $(30 \mu \mathrm{g})$, Cefepime (30 $\mu \mathrm{g})$, Ceftriaxone $(30 \mu \mathrm{g})$, Cefoxitin $(30 \mu \mathrm{g})$, Ciprofloxacin (5 $\mu \mathrm{g})$, Aztreonam (30 $\mu \mathrm{g})$, Gentamicin (10 $\mu \mathrm{g})$, Imipenem (10 $\mu \mathrm{g})$ and Meropenem $(10 \mu \mathrm{g})$. All the antibiotic discs were purchased from Mast Co., UK. E. coli ATCC25922 ( $\beta$ lactamase negative) and $K$. pneumoniae ATCC700603 (ESBL positive) strains were used as controls of the susceptibility testing.

\subsection{Screening of ESBLS With Combination Disc Method}

In brief, pairs of discs containing cefotaxime ( $30 \mu \mathrm{g})$ and ceftazidime $(30 \mu \mathrm{g})$ with and without clavulanic acid (10 $\mu \mathrm{g}$ ), were placed on opposite sides (at a distance of 20 - 30 $\mathrm{mm}$ ) of one inoculated plate containing Muller Hinton agar. A positive test result was defined as a $\geq 5 \mathrm{~mm}$ increase in the zone diameter compared to a disk without clavulanic acid (18).

\subsection{PCR for Detection of Involved Genes}

DNA was extracted from the bacterial colony by simple boiling method. Using template DNA, the polymerase chain reaction technique (PCR) was used to detect SHV1, TEM-1 and CTX-M-1 genes. Primers used to amplify the screened genes are listed in Table 1 (19).

\begin{tabular}{ll}
\hline Table 1. Primer Sequences Used in PCR Amplification \\
\hline Genes & Primer Sequence \\
\hline bla SHV-1 & F:5'ATGAGTATTCAACATTTCCG 3' \\
& R:5' CCAATGCTTATTCAGTGAGG 3' \\
blaTEM-1 & F:5' CTGGGAAACGGAACTGAATG 3' \\
& R:5' GGGGTATCCCGCAGATAAAT 3' \\
blaCTX-M-1 & F:5' GACGATGTCACTGGCTGAGC 3' \\
& R: 5'AGCCGCCGACGCTAATACA 3' \\
\hline
\end{tabular}

DNA amplification was performed in an Eppendorf thermal cycler (Roche Co., Germany) in a final volume of $25 \mu \mathrm{L}$ containing $2.5 \mu \mathrm{L}$ of $10 X$ PCR buffer, $0.8 \mathrm{mg} / \mu \mathrm{L} \mathrm{MgCl}_{2}$, $200 \mu \mathrm{M}$ of dNTP mix, $10 \mathrm{pM}$ of each primer, $0.5 \mathrm{U}$ of Taq polymerase and $5 \mu \mathrm{L}$ of the template DNA. PCR conditions for the SHV-1 gene comprised an initial denaturation step for 5 minutes at $95^{\circ} \mathrm{C}$, followed by 32 cycles of $94^{\circ} \mathrm{C}$ for 1 minute, $57^{\circ} \mathrm{C}$ for 1 minute and $70^{\circ} \mathrm{C}$ for 1 minute, with a final extension step at $72^{\circ} \mathrm{C}$ for 10 minutes. For TEM-1, the amplification cycle consisted of 5 minutes at $95^{\circ} \mathrm{C}$, followed by 30 cycles of $94^{\circ} \mathrm{C}$ for 30 seconds, $55^{\circ} \mathrm{C}$ for 1 minute and $72^{\circ} \mathrm{C}$ for 1 minute, with extension at $72^{\circ} \mathrm{C}$ for 10 minutes. For CTX-M-1, the amplification cycle consisted of 5 minutes at $94^{\circ} \mathrm{C}$, followed by 30 cycles of $94^{\circ} \mathrm{C}$ for 30 seconds, $55^{\circ} \mathrm{C}$ for 1 minute and $72^{\circ} \mathrm{C}$ for 1 minute, with extension at $72^{\circ} \mathrm{C}$ for 10 minutes.

The primers used in the abovementioned reactions can amplify the DNA fragments correspond to 308 base pair (bp) of SHV-1 gene, 858 bp of TEM-1 gene and 499 bp of CTX-M-1 gene. K. pneumoniae strain ATCC700603 and $E$. coli ATCC25922 were used as positive and negative controls, respectively. The PCR products were loaded on a $2 \%$ (w/v) agarose gel with $0.5 \mathrm{mg} / \mathrm{mL}$ ethidium bromide and were analyzed by gel electrophoresis. SPSS software (SPSS Inc no. 13) was used for data analysis. 


\section{Results}

In this study, among 500 clinical isolates of Entrobacteriaceae tested, 55 (11\%) were identified as K. pneumoniae. These isolated were from 12 male $(21.82 \%)$ and 43 female (78.18\%) patients. The majority of the isolates were obtained from urine samples [39 (70.9\%)] and the remaining $[14(29.1 \%)]$ from wound discharge.

Based on the result of combination disc method, 26 (47.27\%) of K. pneumoniae isolates were ESBLs positive and 29 (52.73\%) were ESBLs negative. According to the primary antimicrobial susceptibility testing, which is represented in Table 2, the majority of ESBL positive isolates showed high resistance to most of the tested antibiotics with highest rate of resistance to amoxicillin-clavulanic acid (100\%), followed by amoxicillin (97.89\%) and ampicillin (96.36\%). Data analysis indicated that carbapenems (imipenem and meropenem) showed higher antibacterial activity against K. pneumoniae. The results of PCR method showed that the prevalence of SHV-1, TEM-1 and CTX-M-1 genes among ESBLs-positive isolates were 12 (46.15\%) [ Figure $1 \mathrm{a}$ ], 9 (34.61\%) [ Figure 1 b], and 7 (26.92\%) [ Figure 1 c], respectively. furthermore, both genes of TEM-1 and SHV-1 were seen in four of the isolates (15.38\%).

Table 2. Antimicrobial Susceptibility Pattern of K. pneumonia ESBL producing strains Using Disc Diffusion Method

\begin{tabular}{|c|c|c|c|}
\hline Antibiotic & Susceptible, \% & Intermediate, \% & Resistant, \% \\
\hline Amoxicillin & 0 & 2.91 & 97.89 \\
\hline Amoxicillin/clavulanic acid & 0 & 0 & 100 \\
\hline Ampicillin & 1.82 & 1.81 & 96.36 \\
\hline Amikacin & 9.1 & 25.45 & 65.4 \\
\hline Aztreonam & 40 & 14.54 & 45.46 \\
\hline Cefepime & 52.73 & 5.45 & 41.82 \\
\hline Cefotaxime & 23.64 & 14.54 & 61.82 \\
\hline Cefoxitin & 0 & 5.45 & 94.55 \\
\hline Ceftazidime & 0 & 12.73 & 87.27 \\
\hline Ceftriaxone & 36.36 & 18.18 & 45.46 \\
\hline Cefuroxime & 0 & 10.91 & 89.09 \\
\hline Ciprofloxacin & 29.09 & 38.18 & 32.73 \\
\hline Gentamicin & 12.73 & 36.37 & 50.9 \\
\hline Imipenem & 63.63 & 21.82 & 14.55 \\
\hline Meropenem & 49.1 & 20 & 30.9 \\
\hline Piperacillin & 1.82 & 23.63 & 74.55 \\
\hline Piperacillin/tazobactame & 1.82 & 20 & 78.18 \\
\hline
\end{tabular}

\section{Discussion}

K. pneumoniae strains producing various types of ESBL enzymes have spread worldwide. Among $\beta$-lactam molecules, carbapenems (imipenem, ertapenem, and meropenem) are the drugs of choice for treating infections by ESBL-producing Enterobacteriaceae (20). In this study, imipnem and meropenem were the most susceptible antibiotics against K. pneumoniae isolates (63.63\% and 49.1\% respectively). Though the first imipenem resistant strain isolated from a wound surgery was reported from Iran by Feizabadi et al. (21), however, imipenem was shown to be the most effective antibiotic against these isolates, as reported by another study from Iran (22).

Amoxicillin-clavulanic acid was the first $\beta$-lactam/ beta lactamase inhibitor combination approved for use in clinical practice, and is predominantly used as an oral preparation, effective against penicillinase- producing bacteria including E. coli, Klebsiellae spp, and P. mirabilis
(23), although we noticed that all isolates were resistant to amoxicillin-clavulanic acid (100\%) which is probably due to the frequent use of this antibiotic to treat infections caused by the members of Enterobacteriaceae (24). Such rate of resistance was also reported from Malaysian hospitals (25).

In the present study, the most prevalent ESBL genes were SHV-1, followed by TEM-1. Although TEM-1 was defined as the most frequent gene among ESBL producers in 1980s and early 1990, nowadays there are reports presenting SHV-1 as the most prevalent gene in many parts of the world (37). Similar to our findings, the prevalence of SHV1 and TEM-1 among ESBL-producing K. pneumoniae strains in the study of Eftekhar et al. were $43.14 \%$ and $35.29 \%$ which were close to our findings, however their reported rate of CTX-M-1 gene was higher (31.37\%) compared to this study (38). In a recent study from Iran, ESBL-producing $K$. pneumoniae was reported as $30.5 \%$ with the rate of $57 \%$ for SHV-1and TEM-1 (39). 
Figure 1. Gel Electrophoresis of the PCR Amplification Using SHV-1 (a), TEM-1 (b), and CTX-M-1(c) Genes Specific Primers
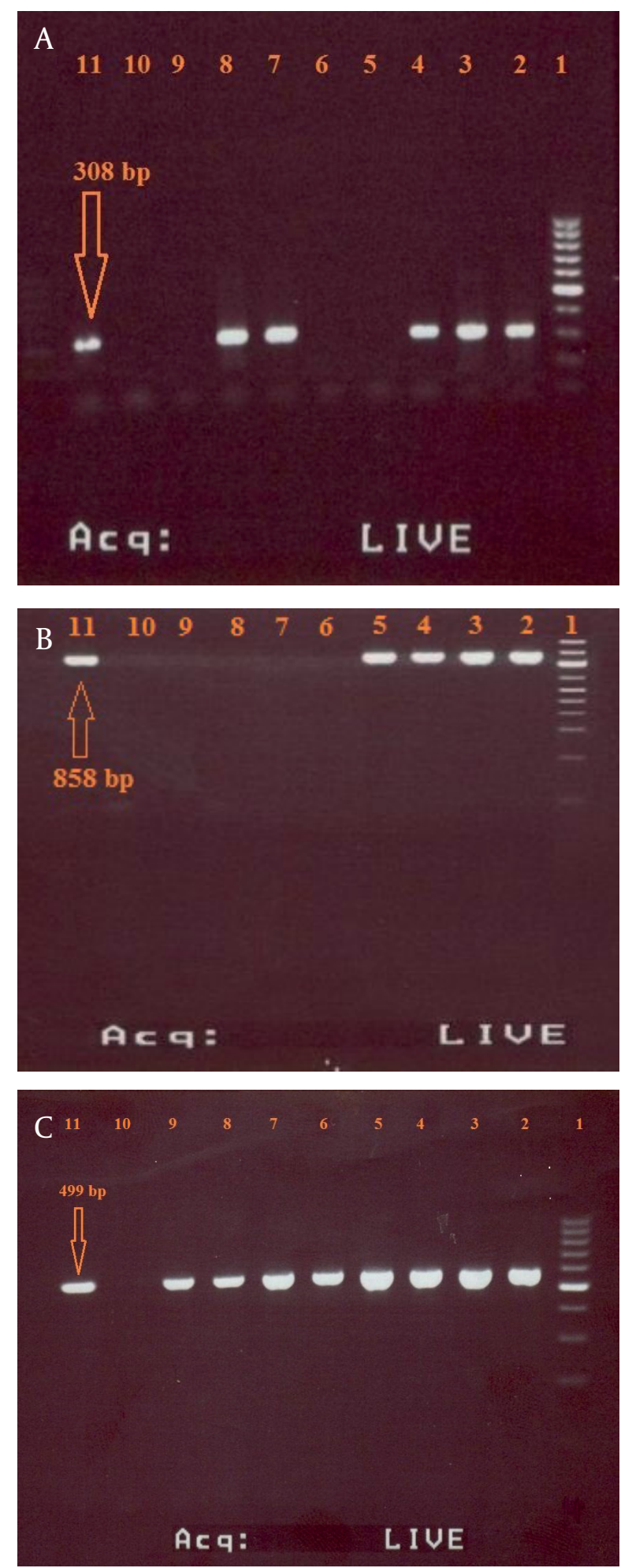

Lanes: 1, molecular size marker; 2 - 9, clinical samples; 10, negative control; 11, positive control.
Data analysis revealed that there was no significant correlation between the presence of genes SHV-1, TEM-1 and CTX-M-1 and sex of patients or type of clinical samples (P > $0.05)$. It is necessary to mention that we did not perform sequencing as a preferred complementary method due to some limitations, as the sequencing and comparing with standard strain shows us the probable mutations and the mechanism of resistance.

In conclusion, the rate of ESBL-producing K. pneumoniae was $47.27 \%$ in the present study showing that these are common in our hospital setting with resistant to many classes of antibiotics, resulting in limited treatment options. The greatest resistance was observed against Amoxicillin-clavulanic acid (100\%) and the lowest rate of resistance was observed for imipenem (14.55\%).

Management of infections resulted from these organisms is difficult and more complex, particularly in severe cases. Therefore, conducting molecular and epidemiological studies will help in identifying various types of ESBLs and establishing the control equipment for such strains in order to prevent and reduce their spread.

\section{Acknowledgements}

This work was approved in Infectious and Tropical Diseases Research center, Jundishapur University of Medical Sciences, Ahvaz, Iran. Special thanks to the research affairs of the University for the Grant (No. 90133) and their continuous support.

\section{Authors' Contribution}

Azar Dokht Khosravi: study design, Study management and supervision, MS preparation. Hajar Hoveizavi and Manijeh Mehdinejad: sampling, processing and performing the conventional and molecular procedures.

\section{Financial Disclosure}

We hereby declare that there are no financial interests related to the material in this manuscript.

\section{Funding/Support}

This work was financially supported by grant No. 90133 from Research affaires, Jundishapur University of Medical Sciences, Ahvaz, Iran. The equipment used in this work was provided by Infectious and Tropical Diseases Research center of the university, where the work has been carried out.

\section{References}

1. Oteo J, Cuevas O, Lopez-Rodriguez I, Banderas-Florido A, Vindel A Perez-Vazquez M, et al. Emergence of CTX-M-15-producing Klebsiella pneumoniae of multilocus sequence types 1, 11, 14, 17, 20, 35 and 36 as pathogens and colonizers in newborns and adults. $J$ Antimicrob Chemother. 2009;64(3):524-8.

2. Herwana E, Pudjiadi YL, Surjawidjaja JE, Lesmana M. Prevalence of extended spectrum beta-lactamase in Klebsiella pneumonia. 
Univ Med. 2008;27:98-105.

3. Fankhauser C, Zingg W, Francois P, Dharan S, Schrenzel J, Pittet D, et al. Surveillance of extended-spectrum-beta-lactamase-producing Enterobacteriaceae in a Swiss Tertiary Care Hospital. Swiss Med Wkly. 2009;139(51-52):747-51.

4. Kang CI, Kim SH, Park WB, Lee KD, Kim HB, Kim EC, et al. Bloodstream infections due to extended-spectrum beta-lactamaseproducing Escherichia coli and Klebsiella pneumoniae: risk factors for mortality and treatment outcome, with special emphasis on antimicrobial therapy. Antimicrob Agents Chemother. 2004;48(12):4574-81.

5. Lin CF, Hsu SK, Chen CH, Huang JR, Lo HH. Genotypic detection and molecular epidemiology of extended-spectrum beta-lactamase-producing Escherichia coli and Klebsiella pneumoniae in a regional hospital in central Taiwan. J Med Microbiol. 2010;59(Pt 6):665-71.

6. Pitout JD, Nordmann P, Laupland KB, Poirel L. Emergence of Enterobacteriaceae producing extended-spectrum betalactamases (ESBLs) in the community. J Antimicrob Chemother. 2005;56(1):52-9.

7. French GL, Shannon KP, Simmons N. Hospital outbreak of Klebsiella pneumoniae resistant to broad-spectrum cephalosporins and beta-lactam-beta-lactamase inhibitor combinations by hyperproduction of SHV-5 beta-lactamase. J Clin Microbiol. 1996;34(2):358-63.

8. Lin TL, Tang SI, Fang CT, Hsueh PR, Chang SC, Wang JT. Extended-spectrum beta-lactamase genes of Klebsiella pneumoniae strains in Taiwan: recharacterization of shv-27, shv-41, and tem116. Microb Drug Resist. 2006;12(1):12-5.

9. Paterson DL, Bonomo RA. Extended-spectrum beta-lactamases: a clinical update. Clin Microbiol Rev. 2005;18(4):657-86.

10. Pfaller MA, Segreti J. Overview of the epidemiological profile and laboratory detection of extended-spectrum beta-lactamases. Clin Infect Dis. 2006;42 Suppl 4:S153-63.

11. Walther-Rasmussen J, Hoiby N. Cefotaximases (CTX-M-ases), an expanding family of extended-spectrum beta-lactamases. Can J Microbiol. 2004;50(3):137-65.

12. Soge OO, Queenan AM, Ojo KK, Adeniyi BA, Roberts MC. CTX-M-15 extended-spectrum (beta)-lactamase from Nigerian Klebsiella pneumoniae. I Antimicrob Chemother. 2006;57(1):24-30.

13. Doi Y, Adams-Haduch JM, Shivannavar CT, Paterson DL, Gaddad SM. Faecal carriage of CTX-M-15-producing Klebsiella pneumoniae in patients with acute gastroenteritis. Indian J Med Res. 2009;129(5):599-602.

14. Kim J, Lim YM. Prevalence Of CTX-M extended-spectrum betalactamases in clinical isolates of Entrobacteriaceae in Korea. $J$ Bacteriol Virol. 2004;34:303-10.

15. Baby Padmini S, Appala Raju B, Mani KR. Detection of Enterobacteriaceae producing CTX-M extended spectrum beta-lactamases from a tertiary care hospital in south India. Indian J Med Microbiol. 2008;26(2):163-6.

16. Forbes BA, Sahm DF, Weissfeld AS. Bailey \& Scott's Diagnostic Microbiology. 12 edSt. Louis: Mosby Inc.; 2007.

17. Clinical and Laboratory Standards Institute. Performance standards for antimicrobial susceptibility testing. Pennsylvania, USA: 12th Informational Supplement; 2002.

18. Naseer U, Natas OB, Haldorsen BC, Bue B, Grundt H, Walsh TR, et al. Nosocomial outbreak of CTX-M-15-producing E. coli in Norway. APMIS. 2007;115(2):120-6.

19. Dashti AA, Jadaon MM, Gomaa HH, Noronha B, Udo EE. Transmission of a Klebsiella pneumoniae clone harbouring genes for CTXM-15-like and SHV-112 enzymes in a neonatal intensive care unit of a Kuwaiti hospital. J Med Microbiol.2010;59(Pt 6):687-92.

20. Raveh D, Yinnon AM, Broide E, Rudensky B. Susceptibilities of ESBL-producing Enterobacteriaceae to ertapenem, meropenem and piperacillin-tazobactam with and without clavulanic acid. Chemotherapy. 2007;53(3):185-9.

21. Feizabadi MM, Etemadi G, Yadegarinia D, Rahmati M, Shabanpoor S, Bokaei S. Antibiotic-resistance patterns and frequency of extended-spectrum beta-lactamase-producing isolates of Klebsiella pneumoniae in Tehran. Med Sci Monit. 2006;12(11):BR362-5.

22. Mehrgan H, Rahbar M, Arab-Halvaii Z. High prevalence of extended-spectrum beta-lactamase-producing Klebsiella pneumoniae in a tertiary care hospital in Tehran, Iran. J Infect Dev Ctries. 2010;4(3):132-8.

23. Bradford PA. Extended-spectrum beta-lactamases in the 21st century: characterization, epidemiology, and detection of this important resistance threat. Clin Microbiol Rev. 2001;14(4):933-51.

24. Avci IY, Kilic S, Acikel CH, Ucar M, Hasde M, Eyigun CP, et al. Outpatient prescription of oral antibiotics in a training hospital in Turkey: trends in the last decade. J Infect. 2006;52(1):9-14.

25. Loh LC, Chin HK, Chong YY, Jeyaratnam A, Raman S, Vijayasingham $\mathrm{P}$, et al. Klebsiella pneumoniae respiratory isolates from 2000 to 2004 in a Malaysian hospital: characteristics and relation to hospital antibiotics consumption. Singapore Med J. 2007;48(9):813-8.

26. Winokur PL, Canton R, Casellas JM, Legakis N. Variations in the prevalence of strains expressing an extended-spectrum betalactamase phenotype and characterization of isolates from Europe, the Americas, and the Western Pacific region. Clin Infect Dis. 2001;32 Suppl 2:S94-103.

27. Kader AA, Kumar A. Prevalence and antimicrobial susceptibility of extended-spectrum beta-lactamase-producing Escherichia coli and Klebsiella pneumoniae in a general hospital. Ann Saudi Med. 2005;25(3):239-42.

28. Bouchillon SK, Johnson BM, Hoban DJ, Johnson JL, Dowzicky MJ, Wu DH, et al. Determining incidence of extended spectrum betalactamase producing Enterobacteriaceae, vancomycin-resistant Enterococcus faecium and methicillin-resistant Staphylococcus aureus in 38 centres from 17 countries: the PEARLS study 20012002. Int J Antimicrob Agents. 2004;24(2):119-24.

29. Daoud Z, Hakime N. [Prevalence and susceptibility patterns of extended-spectrum betalactamase-producing Escherichia coli and Klebsiella pneumoniae in a general university hospital in Beirut, Lebanon]. Rev Esp Quimioter. 2003;16(2):233-8.

30. Yaman A, Tasova Y, Kibar F, Inal AS, Saltoglu N, Buyukcelik O, et al. Investigation of the antibiotic susceptibility patterns of pathogens causing nosocomial infections. Saudi Med I. 2004;25(10):1403-9.

31. Shehabi AA, Mahafzah A, Baadran I, Qadar FA, Dajani N. High incidence of Klebsiella pneumoniae clinical isolates to extendedspectrum B-lactam drugs in intensive care units. Diagn Microbiol Infect Dis. 2000;36(1):53-6.

32. Jabeen K, Zafar A, Hasan R. Frequency and sensitivity pattern of Extended Spectrum beta Lactamase producing isolates in a tertiary care hospital laboratory of Pakistan. J Pak Med Assoc. 2005;55(10):436-9.

33. Feizabadi MM, Mahamadi-Yeganeh S, Mirsalehian A, Mirafshar SM, Mahboobi M, Nili F, et al. Genetic characterization of ESBL producing strains of Klebsiella pneumoniae from Tehran hospitals. Infect Dev Ctries. 2010;4(10):609-15.

34. Aminzadeh Z, Sadat Kashi M, Sha'bani M. Bacteriuria by extended-spectrum Beta-lactamase-producing Escherichia coli and Klebsiella pneumoniae: isolates in a governmental hospital in South of Tehran, Iran. Iran J Kidney Dis. 2008;2(4):197-200.

35. Behrooozi A, Rahbar M, Yousefi JV. Frequency of extended spectrum beta-lactamase (ESBLs) producing Escherichia coli and klebseilla pneumonia isolated from urine in an Iranian 1000bed tertiary care hospital. Afr J Microbiol Res. 2010;4:881-4.

36. Irajian G, Jazayeri-Moghadas A, Beheshti A. Prevalence of extended-spectrum beta lactamase positive and multidrug resistance pattern of Escherichia coli and Klebsiella pneumoniae isolates, Semnan, Iran. Iran J Microbiol. 2009;1:49-53.

37. Kiratisin P, Apisarnthanarak A, Laesripa C, Saifon P. Molecular characterization and epidemiology of extended-spectrum-betalactamase-producing Escherichia coli and Klebsiella pneumoniae isolates causing health care-associated infection in Thailand, where the CTX-M family is endemic. Antimicrob Agents Chemother 2008;52(8):2818-24.

38. Eftekhar F, Rastegar M, Golalipoor M, Mansoursamaei N. Detection of Extended Spectrum B-Lactamases in Urinary Isolates of Klebsiella pneumoniae in Relation to Bla, Bla and Bla Gene Carriage. Iran J Public Health. 2012;41(3):127-32.

39. Moosavian M, Deiham B. Distribution of TEM, SHV and CTX-M Genes among ESBL-producing Enterobacteriaceae isolates in Iran. Afr J Microbiol Res. 2012;6:5433-9. 